\title{
THE POWER OF WONDER BY R. J. PALACIO TO TRIGGER YOUNG READERS’ EMOTIONALLY LITERATE RESPONSES
}

\author{
RALUCA-STEFANIA PELIN \\ "Ion Ionescu de la Brad” Iaşi University of Life Sciences
}

\begin{abstract}
Readers' emotions are naturally blended with their cognitive abilities in the transaction with literary texts. From the perspective of emotional intelligence, an emotionally literate reader will be able to read beyond the surface of the text and make inferences regarding shades of feelings, their causes and effects. The purpose of the present study was to observe whether there is any correlation between the emotional intelligence profile of young readers and their abilities to identify the emotional input in literary texts and its impact on themselves. The study was carried out with the participation of 72 students in the first year at the Faculty of Letters in Iași. It consisted in three stages and relied both on quantitative and qualitative data collection. In the first stage, the students filled in a Reading literary texts - Self-report questionnaire; in the second stage they filled in the How Empathetic are You? (The Toronto Empathy Questionnaire, TEQ) ("How Empathetic") and in the third stage they were given excerpts from the book Wonder by R. J. Palacio in order to check whether the self-reported emotional literacy skills were at work when approaching a literary text. Approximately half of the students (30) offered to watch the film prior to class discussion and work. The answers were compared with the results of the self-reported questionnaires and a natural and fairly consistent correspondence between the profiles of readers in terms of empathy in general and the empathy felt with regard to the fictional characters together with a good command of emotion vocabulary could be observed.
\end{abstract}

Keywords: reader-response, characters' feelings, emotional intelligence, emotional literacy skills, empathy. 


\section{INTRODUCTION}

Regardless of the texts they approach, readers are bound to experiment emotions in all the phases of the reading process. Throughout the encounter with the fictional world, the reader may experience emotions of sympathy, identification or empathy given the context in which the characters are placed, their emotional configuration as well as their inclination to answer to situations. The readers' response to literary texts is therefore a combination of emotion perception, labelling, expression and assimilation competences.

The students at the Faculty of Letters are expected to invest a lot of their time in reading both fictional and nonfictional texts and be able to use the acquired information in various academic contexts culminating sometimes in a career in teaching. Therefore, they should be well equipped with both critical thinking and emotional literacy skills so as to make sense of what they are reading and of the impact of texts on themselves and on those they may be interacting with or teaching. In order to assess the level of students' emotional intelligence abilities in relation to reading, a special Reading literary texts - Selfreport questionnaire has been devised following the Four-Branch Model of Emotional Intelligence proposed by the psychologists John D. Mayer and Peter Salovey (Mayer and Salovey 11) and applied to students as part of the doctoral research (Pelin 2020). From this ample study, only the answers to the questions related to the perception, expression and impact of emotions have been selected. Moreover, the study focused on the correlation between the readers' level of empathy measured by How Empathetic are You? (The Toronto Empathy Questionnaire, TEQ) ("How Empathetic"), readily available for use by all categories of professionals, and their emotional literacy skills. The reading task used in the present study for exemplification consisted of some fragments from the novel Wonder by R. J. Palacio, a New York Times bestseller which was also made into a film released in 2017. The subject matter manages to challenge the reader not only to intense emotions but also to a play on perspectives which makes the grasp of the big picture an intricate and rewarding experience.

The conclusions drawn from observing the way students handled the emotional substance of the book in accordance to their emotional profile and skills may be linked to the assumption stated by Norman N. Holland in his book Literature and the Brain where the author highlights the universal character of emotions, offering us the certainty that the ability to recognise similar emotions in given circumstances is shared at the level of reading communities:

This universality argues that our emotional systems are innate, built genetically into our physiology. To the extent that we humans feel emotion through a vocabulary of fixed emotions (rage, disgust, fear, joy, anger, and so on), many 
people will share the same emotional response to a given work of literature. (Holland 84)

The variables of this study however derive from the level of the command of the English language - since the students had English as their minor, as well as from the degree of truthfulness in claiming they have watched the film - as this was given as an optional home assignment. Nevertheless, most of the reviews handed in and the discussions in class were imbued with heartfelt testimonies of the impact the film had on themselves. The students' post-film discussion brought to light actual issues students - particularly those in secondary schools - have to face when it comes to bullying and acceptance among the peers, issues that leave a strong imprint on their personality in the long run. The students turned into ardent advocates of the right of each child or teenager to be accepted and appreciated just as he or she is and made strong pleas against the spread of bullying in schools and other educational institutions.

The concepts of emotional intelligence and emotional literacy skills have been developed extensively in the past decades with a special focus on their validity and efficiency in educational or entrepreneurial contexts. The focus of the present study is to see how this field can be merged with that of reader's reception and reader's response theories at the level of literary studies in order to see whether the knowledge acquired in the aesthetic phase of the reading process may gain practicality in the real-life context of readers.

\section{READING RECEPTION AND READER-RESPONSE THEORIES}

Reading reception and reader-response theorists have been mainly concerned with the way readers are exposed to emotions in their encounter with books (Oatley 1994; Cupchik et al. 1998; Holland 2009; Hogan 2011) in a double posture: the "external" mode comprising the emotions readers experience when "confronting the text" and also the "internal" mode referring to the emotions readers feel while "entering the world of the text" (Oatley, A taxonomy 57). The main focus is on how the readers assimilate and accommodate the "schema" of emotions (Oatley, A taxonomy 57) - their own and the one proposed by the author. The emotions readers experience in the process of reading range from empathy (Nussbaum 1997, 2001; Keen 2007) and sympathy (Sklar 2013) to various other positive and negative feelings (Oatley 2004) depending on the genre and the meaning the readers derive from the text. Furthermore, there have been numerous attempts to take the matter a little further and see the manner in which feelings are acknowledged by readers and consciously directed or steered in the encounter with the text. Such studies were especially conducted by 
Norman Holland (1977, 1978, 2004, 2009), Keith Oatley (2004, 2011, 2012) and Patrick Colm Hogan (2001, 2003, 2011).

In "Emotion and narrative fiction: Interactive influences before, during, and after reading" (2011) Mar, Oatley, Djikic and Mullin start from the taxonomy proposed by Keith Oatley in his article "A taxonomy of the emotions of literary response and a theory of identification in fictional narrative” (1994). The distinction they make is between the aesthetic emotions, which refer to the perception of the literary work as a whole and form "an aesthetic distance" and the emotions experienced when entering the narrative world, which in turn are classified as "fresh emotions" triggered when the reader perceives the protagonist and his or her inner or outer world, and the emotions triggered by memories, the "remembered emotions" (Mar et al. 818-83). Those are the emotions lived at cognitive level mainly, when the reader tries to make sense of the personality of the character, its inner emotional and cognitive structure, and the intents or "goals" he or she may have all along the moments of the plot. Throughout the encounter with the fictional world, the reader may experience emotions of "sympathy, identification, empathy" given the context in which the characters are placed and their emotional configuration and inclination to answer to situations. When the text incidentally meets with the reader's experience, the "remembered" emotions may be relieved or may remain at the cognitive level, depending on the reader's inclination to be strongly or only slightly moved from the emotional point of view.

The overlap between the domain of emotions and that of literature is probably best represented in the transaction that ensues between the text and the reader, a process which comprises various stances clearly defined by the proponents of this theory. Hans Robert Jauss' "horizon of expectations" and the freedom of the Self in the act of reading (1982), Wayne C. Booth's perspectives on the attitudes manifested by readers in the act of reading (1983), Wolfgang Iser's concept of "indeterminacy" (1997) that leaves an open space - a gap - to readers' filling in meaning, and the concept of "transaction" extensively supported by David Bleich (1997), Louise M. Rosenblatt (1960, 1982, 1986) and Norman Holland (1977, 1978, 1992, 2009), who place the reader in the position of handling the literary matter according to one's own identity, expectations and power to give meaning to the written word and beyond. Louise M. Rosenblatt highlights the importance of having meaningful encounters with literature particularly with the purpose of building empathy, a core concept in the field of emotional intelligence, which she defines as "a capacity essential in democracy, where we need to rise above narrow self-interest and envision the broader human consequences of political decisions" (cf. Karolides 169). In Empathy and the Novel Suzanne Keen acknowledges the wide acceptance of the fact that 
readers do experience a state of empathy-altruism which they carry from the confines of the reading process into the real world. However, she is not sure of the real impact and extension of such activation of feelings in real life stating that: "There is no question, however, that readers feel empathy with (and sympathy for) fictional characters and other aspects of fictional worlds.” (Keen vii) and adds that there is no "proven connection between reading and feeling empathy and the manifestation of altruism in real life" (Keen viii).

\section{EMOTIONS, EMOTIONAL INTELLIGENCE AND EMOTIONAL LITERACY SKILLS}

The readers' interaction with literary texts extends beyond the mere act of reading and decoding information. The mental processes involved in decoding lexical and emotional information and in making sense of the web of relations are reflected in psychology in the field of emotion studies, emotional intelligence and the acquisition of emotional intelligence competences. A significant and revelatory trajectory of thoughts on the continuum of reading processes should start from a clear definition of all the concepts enumerated above. Emotions are defined in ways that closely link more areas of the human being. Peter Salovey and John. D. Mayer view emotions as:

... organized responses, crossing the boundaries of many psychological subsystems, including the physiological, cognitive, motivational and experiential systems. Emotions typically arise in response to an event, either internal or external, that has a positively or negatively valenced meaning for the individual. Emotions can be distinguished from the closely related concept of mood in that emotions are shorter and generally more intense.” (Salovey and Mayer 186)

Moreover, they consider "the organized response of emotions" as "adaptive and as something that can potentially lead to a transformation of personal and social interaction into enriching experience”. (Salovey and Mayer 186) Bridging the field of literary studies to that of psychology and more precisely to that of emotional intelligence that deals with emotions in all their complexity, a clearer and more productive perspective unfolds. Daniel Goleman, who popularized the concept of emotional intelligence, states that the root of altruism lies in "empathy, the ability to read emotions in others; lacking a sense of another's need or despair, there is no caring” (Goleman xiii).

John D. Mayer and Peter Salovey, the proponents of the concept of emotional intelligence, suggest a Four-Branch Model of Emotional Intelligence (Mayer and Salovey 11) which offers a ranking of abilities from those perceived 
by the authors as "simple" (Mayer and Salovey 10) to those that involve higher mental processes:

- $\quad$ Perception, Appraisal and Expression of Emotion

- $\quad$ Emotion Assimilation and Facilitation of Thinking

- $\quad$ Emotion Understanding and Use of Emotional Knowledge

- $\quad$ Emotion Management

The model may provide literary studies with valuable tools in observing readers throughout the process of their transaction with the literary text. Each branch presents a gradual consideration of aspects involved in mental and emotional processing and use of information. The first branch Perception, Appraisal and Expression of Emotion is placed by the authors at the bottom of their model as it presumably covers the skills people are naturally expected to master since childhood. The ability to recognise how one feels and acknowledge similar emotions in others is mastered by human beings from a very early age. The other branches entail an equal degree of relevance to the force of emotions on the cognitive and behavioural propensities of a person.

Within the scope of this study from the Reading literary texts - Selfreport questionnaire only those questions related to the perception, expression, assimilation of emotions as well as those related to emotion understanding have been selected. The answers to these questions have been compared with the students' responses to the literary fragments.

\section{METHODOLOGY}

The present research has been performed both quantitatively and qualitatively with the aim of observing the impact of an emotionally challenging text on students as well as on their ability to produce relevant emotional lexis starting from the given literary input.

Participants: The study was done with participation of 72 freshmen-60 female and 12 male readers-all studying literature at the Faculty of Letters in Iași, minoring in English. During the practical course on literature the students were familiarized with the opinions of various writers, such as Virginia Woolf and Vladimir Nabokov, on readers and writers and with perspectives on approaching literary texts offered by Jonathan Culler in Literary Theory: A Very Short Introduction (1997) and Louise M. Rosenblatt in her article "The Literary Transaction: Evocation and Response" (1982). The literary texts analysed during the course were poems, short texts or fragments from novels and the entire novel The Remains of the Day, by Kazuo Ishiguro. All the texts had to a certain degree centered on emotions or the way characters used them in various circumstances. 
A special course meeting was dedicated to a discussion of the book Wonder by R. J. Palacio.

Data Collection Tools: The data were collected in three stages. The first two stages consisted in applying two questionnaires: the Reading literary texts - Selfreport questionnaire and the How Empathetic are You? (The Toronto Empathy Questionnaire, TEQ) ("How Empathetic") since it was readily available and easy to interpret.

The Reading literary texts - Self-report questionnaire was devised in keeping with the branches proposed by the authors of the Four-Brach Model of Emotional Intelligence (Mayer and Salovey 1997). As measuring tool was used the Likert scale with values from 1 to 5: 1 (never), 2 (rarely), 3 (sometimes), 4 (often), 5 (always), the frequency reference playing an important part in the way students report on their experience: "With Likert scales, participants are asked to respond to a statement, indicating the degree to which they agree or disagree with it. This is one of the most frequently used techniques in attitude measurement.” (Peer et al. 114) The responses are rendered in graphs for each question, where the number of students is represented on the vertical axis whereas the horizontal axis represents the temporal variants ranging from 1 (never), 2 (rarely), 3 (sometimes), 4 (often) to 5 (always) with each corresponding column indicating how many students opted for a certain variant. For this case study I made the distinction between the male and female readers' responses in order to compare their reactions and competences to their results in the How Empathetic are You? (The Toronto Empathy Questionnaire, TEQ) ("How Empathetic") and their options for various emotion lexical variants.

\section{DISCUSSIONS}

The answers were selected from the first section: Perception, Appraisal and Expression of Emotion. The first statement was formulated so as to bring the respondents closer to the issue under discussion, i.e. of emotions in the texture of literary texts (Figure 1). 


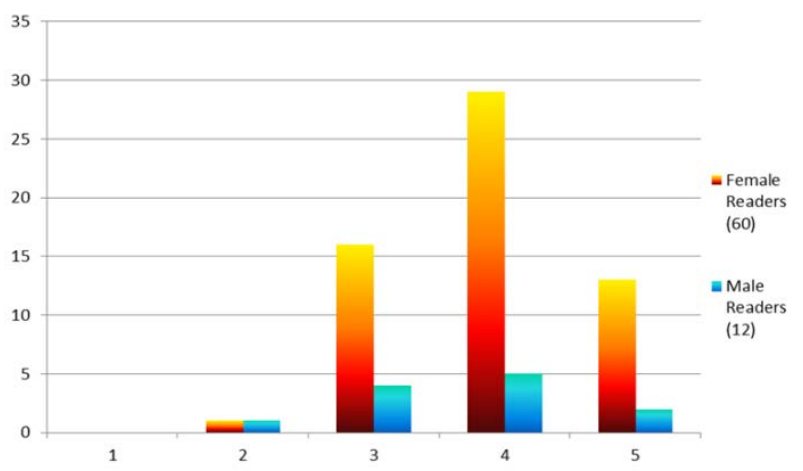

Figure 1. Answers to the statement: I can easily infer when the writer/ narrator is making reference to emotional states (by means of the setting, characters' thoughts, words and actions, etc.).

A further categorization was done in order to distinguish the readers' ability to discern positive and negative emotions starting from the input offered by the authors (Figures 2 and 3).

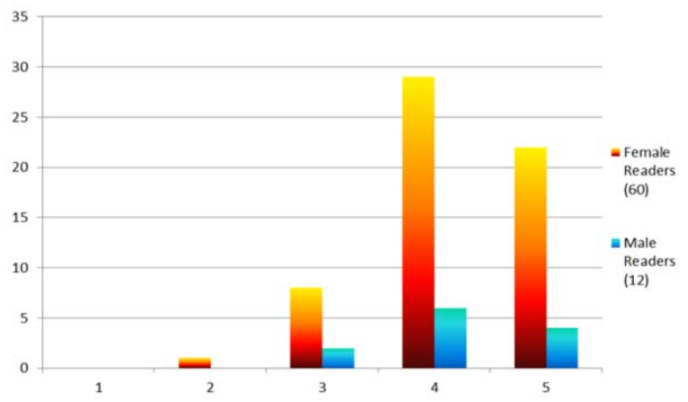

Figure 2. Answers to the statement: I can easily discern the emotions of characters when these are positive (e.g. happiness, thrill, contentment etc.).

The overview offers an optimistic perspective, with half the readers being 'often' able to discern the positive feelings of characters, with a fairly similar consistency for both genders.

In the case of the third statement related to recognising negative emotions (Figure 3), the data show a migration of the female responses from the area of 'sometimes' (3) to those of 'rarely' (2) and 'never' (1). As can be also observed there are fairly similar tendencies for the categories of 5 (always) and 4 (often) among female and male readers with male readers opting for only these two categories. 


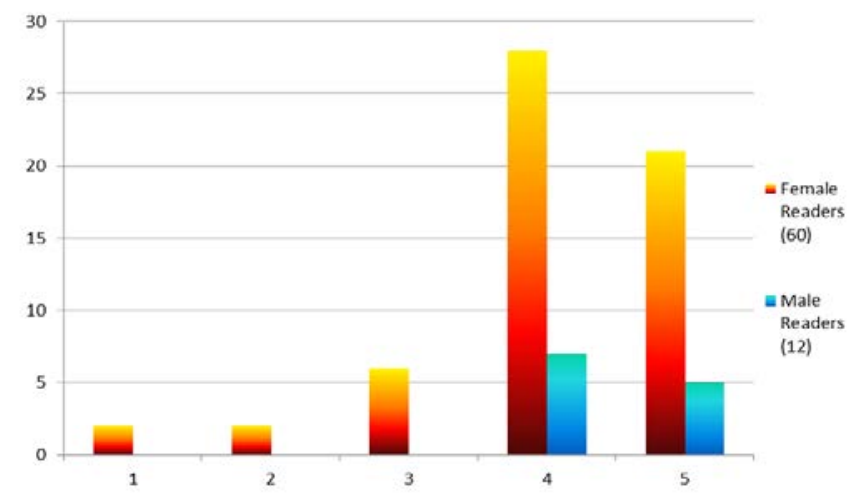

Figure 3. Answers to the statement: I can easily discern the emotions of characters when these are negative (e.g. sadness, distress, discontent etc.).

The concentration of male answers in these two categories may have its roots in the male readers' tendency to struggle with negative feelings more, especially in their adolescence (Turliuc and Marici 2013).

From the second branch of the questionnaire: Emotion Assimilation and Facilitation of Thinking a statement has been selected with the aim of observing what kind of emotions make readers more inclined to identify themselves with the characters. The differences between the values of the emotions indicate that readers would rather identify with characters when the latter experience positive emotions (Figure 4).

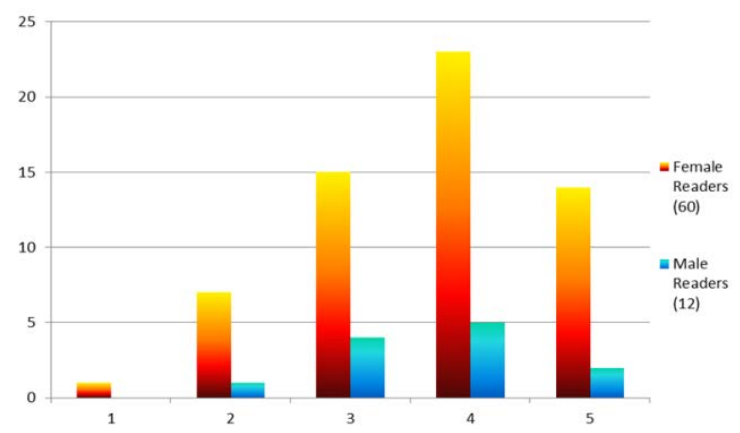

Figure 4. Answers to the statement: I identify myself with the literary characters when these ones experience positive feelings (surprise, happiness, hope, gratitude, confidence etc.) 
The concentration of answers in the areas of 'sometimes' (3), 'often' (4) and always (5) is a promising indicator of the presence of these feelings in readers both at experiential and cognitive level, since the second is a fine processing of the first. Male readers, again, do not opt for the extreme answer of 'never'.

With regard to the negative feelings the distribution of answers seems to indicate a different dynamics (Figure 5). The chart in Figure 5 indicates a slightly higher level of male readers' capacity to 'always' (5) identify with the characters when these ones experience unpleasant feelings and a striking lack of any points at the extreme of 'never'. The migration of answers towards the areas of 'sometimes' and 'rarely' together with the existence of several answers in the area of 'never' may highlight, different experiences, a toughness of character or commitment among female readers to remain unaffected by such feelings.

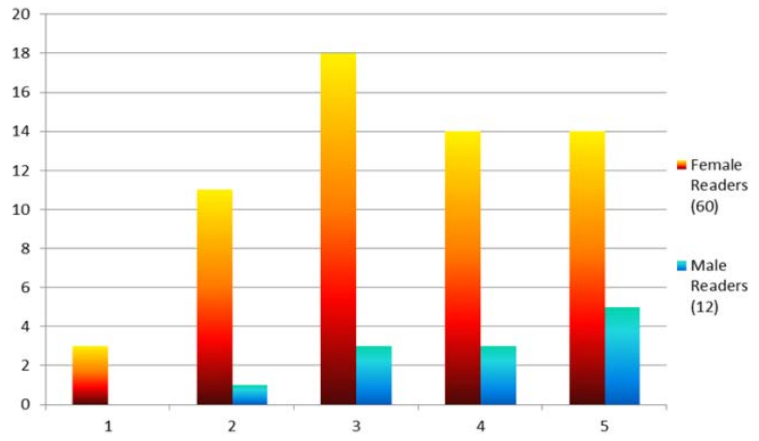

Figure 5. Answers to the statement: I identify myself with the literary characters when these ones experience negative feelings (distress, sadness, fear, anger, disgust etc.).

From the third branch of the questionnaire Emotion Understanding and Use of Emotional Knowledge there have been selected the answers related to the ability of readers to empathise with the characters (Figure 6). 


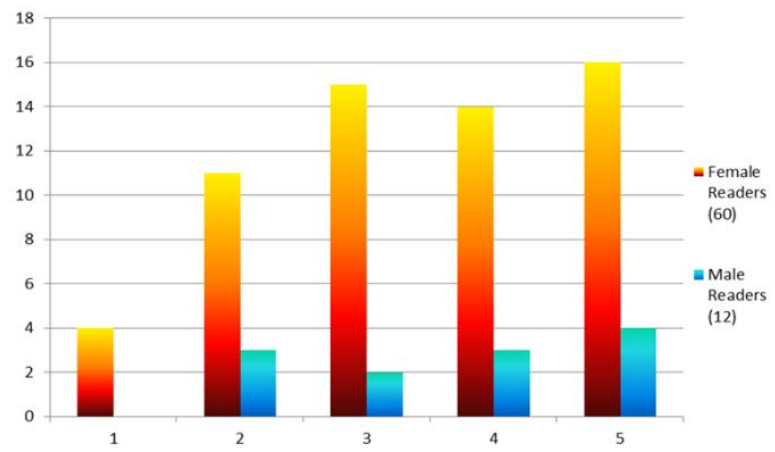

Figure 6. Answers to the statement: I empathise with the characters that experience negative emotional states because I can link them to my experience.

The spread of answers in all the areas is reflected in the answers the students offered when dealing with the literary text and asked whether they empathised or identified with the main character.

The second stage consisted in applying the How Empathetic are You? (The Toronto Empathy Questionnaire, TEQ) ("How Empathetic"). The interpretation of data gathered after the application provides evidence regarding the students' empathy levels in general. According to the interpretation data offered by the authors of the test, males' general scores range from 43.46 to 44.45 and female scores from 44.62 to 49.93 . The data collected from the above mentioned 72 first-year students (60 female students and 12 male students) who study literature bring to light a surprising reality. The male students scored under 43 (6 students), between 43 and 44 (1 student) and above 44 (5 students), while the female students scored under 44 (22 students), between 44 and 49 (19 students) and above 49 (19 students). Some of the students who scored below the indicated average had unexpectedly low scores while some who scored above had surprisingly high scores. These scores shed more light on the way students transacted with the fragments from the novel Wonder by R. J. Palacio and their tendency to manifest empathy towards the fictional character depicted.

In the third stage the students received a material devised for class use in which more fragments were selected from the book in order to check the readers' emotional literacy skills. The present paper only focuses on the first task since it has to do with the perception of emotions, the ability to identify the emotions behind the various lexical hints and the impact of those emotions on the readers in terms of empathy. I make the distinction between the male and female readers' responses in order to compare their reactions and their competences to perceive and express opinions on emotions with the results from the TEQ ("How Empathetic"). Thirty students (twenty-seven female students 
and three male students) offered to watch the film before completing the experiment and wrote a review on it.

The novel chosen for this study - Wonder by R. J. Palacio - presents the story of August Pullman, a ten-year-old boy who has undergone numerous surgeries due to a facial anomaly and has consequently been home-schooled by his mother. August (or Auggie) struggles with the decision of attending school in the fifth grade and when finally determined to do so, he has to face a group of diverse students who either make all the efforts to turn school into a pleasant experience or struggle with multiple contradictory feelings. The current issue of bullying permeates the layers of the novel and brings to light the struggles of all characters that are situated on either side of the conflict.

The reading task comprised three sections. In the first section the students were given two fragments from the novel to read and then name some of the emotions experienced by the main character:

I know I'm not an ordinary ten-year-old kid. I mean, sure, I do ordinary things. I eat ice-cream. I ride my bike. I play ball. I have an Xbox. Stuff like that makes me ordinary. I guess. And I feel ordinary. Inside. But I know ordinary kids don't make other ordinary kids run away screaming in playgrounds. I know ordinary kids don't get stared at wherever they go.

If I found a magic lamp and I could have one wish, I would wish that I had a normal face that no one ever noticed at all. I would wish that I could walk down the street without people seeing me and then doing that look-away thing. Here's what I think: the only reason I'm not ordinary is that no one else sees me that way.

But I'm kind of used to how I look by now. I know how to pretend I don't see the faces people make. We've all gotten pretty good at that sort of thing: me, Mom and Dad, Via. Actually, I take that back: Via's not so good at it. She can get really annoyed when people do something rude. Like, for instance, one time in the playground some older kids made some noises. I don't even know what the noises were exactly because I didn't hear them myself, but Via heard and she just started yelling at the kids. That's the way she is. I'm not that way.

Via doesn't see me as ordinary. She says she does, but if I were ordinary, she wouldn't feel like she needs to protect me as much. And Mom and Dad don't see me as ordinary, either. They see me as extraordinary. I think the only person in the world who realizes how ordinary I am is me.

My name is August, by the way. I won't describe what I look like. Whatever you're thinking, it's probably worse." (Palacio 3)

'Mom? Am I always going to have to worry about jerks like that?' I asked. 'Like when I grow up, is it always going to be like this?' (Palacio 279) 
The answers the readers offered prove that they rely on the direct input from the texts, with many students (twenty-seven) stating that the character feels 'ordinary'. The range extends then to various feelings detected by the readers. The number of times a word is used by the readers is indicated between brackets. The sixty female readers noticed that the main character feels: lonely (16), sad/ upset (12), different from others (8), (over)protected (5), worried (5), insecure (5), confused (4), resigned (4), disappointed (3), angry (2), uncomfortable (2), vulnerable (2), rejected (2), judged (2), marginalized (2), isolated (2), melancholic (2), tired (2), unconfident (2), alienated (2), ashamed, afraid, apprehensive, fearful, ignored, inadequate, abandoned, desperate, anxious, solitary, misunderstood, conflicted, embarrassed, hopeless, annoyed, a little depressed, irritated, inferior, pressured, frustrated, strange, weird, unsatisfied. The female readers also detected some positive feelings as well, ranging from feeling loved, pensive, extraordinary, accepted, comfortable (with himself), appreciated, detached, appeased, unbothered, to even feeling hopeful (3). The twelve male readers similarly agreed that the main character feels: sad (3), lonely (3), disappointed, hopeless, worried, rejected, confused, uncomfortable, strange, vulnerable, embarrassed and different, and added to the list: odd, concerned, desperate, mad, unhappy, disgraceful, persecuted and doubtful, along with the positive feeling of happiness (with himself). The list of emotions enumerated is an encouraging proof that readers can detect various shades of feelings behind the words of the main character, pointing to an emotional literate skill of inferring various emotional intensities behind words.

The second section comprised three clusters of emotions deemed as being present directly or indirectly in the texts. The clusters revolved around negative feelings since they are the ones that mainly lead to feelings of empathy. When asked to choose from given clusters of emotions derived from three basic emotions: sadness, fear and anger the ones they thought described August Pullman's feelings most accurately, some of the readers limited their choice to only one word from each cluster or from some clusters only, while others circled more words even in the same cluster, testifying thus that although some emotions seem similar and fall into the same broad category, they carry more shades of meaning in relation to the reality experienced by the character. The clusters were partially inspired by the way in which emotions are organized in “'I Feel' - Emotional Word Wheel” ("I Feel”), to which I added other nuances I considered relevant for the emotions of the character. Thus, from the first cluster that revolved around the emotion of sadness: loneliness, despair, vulnerability, hurt, the students chose the following variants they thought would be more appropriate to describe the main character's feeling (Table 1). 
Table 1. Students' choices regarding the first cluster that revolved around the emotion of sadness: loneliness, despair, vulnerability, hurt

\begin{tabular}{|c|c|c|c|}
\hline & Name of feeling & Male readers (12) & Female readers (60) \\
\hline \multicolumn{4}{|c|}{ loneliness } \\
\hline 1. & isolation & 4 & 30 \\
\hline 2. & abandonment & 1 & 10 \\
\hline 3. & alienation & 3 & 9 \\
\hline 4. & melancholia & 0 & 8 \\
\hline \multicolumn{4}{|c|}{ despair } \\
\hline 1. & grief & 0 & 7 \\
\hline 2. & powerlessness & 1 & 1 \\
\hline 3. & hopelessness & 2 & 5 \\
\hline 4. & discouragement & 1 & 13 \\
\hline 5. & depression & 0 & 5 \\
\hline \multicolumn{4}{|c|}{ vulnerability } \\
\hline 1. & victimization & 0 & 2 \\
\hline & $\begin{array}{l}\text { fragility (emotional } \\
\text { ity) }\end{array}$ & 3 & 32 \\
\hline 3. & defenselessness & 0 & 7 \\
\hline \multicolumn{4}{|c|}{ hurt } \\
\hline 1. & offence & 0 & 11 \\
\hline 2. & irritation & 1 & 4 \\
\hline 3. & sadness & 3 & 27 \\
\hline
\end{tabular}

The second cluster of emotions was based on the related words for fear. It took students to the level at which the emotions felt involved a possible influence from the others: anxiety, insecurity, rejection, and threat (Table 2).

Table 2. Students' choices regarding the second cluster that revolved around the emotion of fear: anxiety, insecurity, rejection, threat

\begin{tabular}{|c|c|c|c|}
\hline & Name of feeling & Male readers (12) & Female readers (60) \\
\hline \multicolumn{4}{|c|}{ anxiety } \\
\hline 1. & nervousness & 0 & 11 \\
\hline 2. & fear/ fright & 1 & 12 \\
\hline 3. & worry & 4 & 18 \\
\hline 4. & concern & 2 & 10 \\
\hline \multicolumn{4}{|c|}{ insecurity } \\
\hline 1. & inadequacy & 1 & 13 \\
\hline 2. & inferiority & 0 & 22 \\
\hline 3. & vulnerability & 2 & 9 \\
\hline 4. & doubt & 1 & 7 \\
\hline \multicolumn{4}{|c|}{ rejection } \\
\hline 1. & exclusion & 7 & 38 \\
\hline 2. & persecution & 1 & 2 \\
\hline 3. & damnation & 0 & 3 \\
\hline 4. & scorn & 1 & 1 \\
\hline \multicolumn{4}{|c|}{ threat } \\
\hline 1. & ban & 0 & 4 \\
\hline
\end{tabular}




\begin{tabular}{|ll|l|l|}
\hline 2. & intimidation/ menace & 0 & 16 \\
\hline 3. & peril/ jeopardy & 1 & 1 \\
\hline
\end{tabular}

The emotions in the third cluster were selected from the area of anger and offered the following variants: humiliation, bitterness, madness, and frustration (Table 3).

The surprising fact is that, at a very close reading, one could affirm that all the shades of some emotions are actually present in the state of mind August is experiencing. Nevertheless, the students' options reflect slight differences between male and female readers with female readers opting for more lexical variants.

The third section in the reading task devised for students focused on their inclination to empathise or identify with Auggie (the main character). To support their choice, students were asked to bring relevant arguments. Out of the sixty female students, thirty-seven claimed they empathised or tended to empathise with the main character. These students offered well-grounded arguments that indicate that they are capable of imagining what Auggie feels like and his inner struggles. Some of them argued that it is normal to empathise with the character based on the current tendency among people to lay great emphasis on appearance and be very judgmental with regard to appearance, as well as on the fact that bullying cases are frequently present in schools and tend to reach alarming levels. Some female readers empathised in view of their similar personal experience regarding appearance. Other readers empathised with Auggie's plea for being treated as a normal human being. Alternatively, the female readers that claimed to have identified with Auggie (11) brought as arguments their own struggles with issues related to appearance, feelings of inferiority and rejection. Five students did not offer any answer to this question.

Table 3. Students' choices regarding the third cluster that revolved around the emotion of anger: humiliation, bitterness, madness, frustration

\begin{tabular}{|c|c|c|c|}
\hline & Name of feeling & Male readers (12) & Female readers (60) \\
\hline \multicolumn{4}{|c|}{ humiliation } \\
\hline 1. & disrespect & 1 & 20 \\
\hline 2. & ridicule & 0 & 11 \\
\hline 3. & shame & 1 & 12 \\
\hline 4. & embarrassment & 0 & 12 \\
\hline \multicolumn{4}{|c|}{ bitterness } \\
\hline 1. & indignation & 0 & 9 \\
\hline 2. & unhappiness & 4 & 22 \\
\hline 3. & resentfulness & 0 & 4 \\
\hline 4. & spite & 0 & 1 \\
\hline 5. & hatred & 0 & 1 \\
\hline 6. & sarcasm & 0 & 3 \\
\hline 7. & hostility & 1 & 1 \\
\hline \multicolumn{4}{|c|}{ madness } \\
\hline
\end{tabular}




\begin{tabular}{|ll|l|l|}
\hline $1 . \quad$ anger & 0 & 15 \\
\hline $2 . \quad$ fury & 0 & 10 \\
\hline $3 . \quad$ envy & 0 & 0 \\
\hline $4 . \quad$ jealousy & 0 & 2 \\
\hline frustration & 2 & 8 \\
\hline $1 . \quad$ annoyance & 0 & 2 \\
\hline $2 . \quad$ distrust & 0 & 7 \\
\hline $3 . \quad$ impatience & 6 & 20 \\
\hline $4 . \quad$ disappointment & 1 & 17 \\
\hline 5. & dissatisfaction & \multicolumn{2}{l|}{} \\
\hline
\end{tabular}

The male readers claimed they empathised (8) or identified (3) or both (1) or did not identify (1). Those who empathised recognised the need of people confronted with such issues to be understood and comforted; they felt sad for him, or simply claimed to empathise with people in need in general. The students who claimed to identify with the main character referred to what they regarded as similar feelings of disappointment, feeling weird; some students understood Auggie's feelings since they had been through similar personal experiences of being bullied and feeling the need to withdraw. The student who did not identify with the character claimed that he would not complain so much about his looks saying that people should love you for who you are.

Predictably, those students with low scores in the self-reported empathy questionnaire (TEQ) either avoided the question regarding the tendency to empathise or identify with Auggie, or gave rather vague responses. Some of them, on the other hand, offered strong arguments for empathising or identifying with the main characters and even attempted convincing pleas for the need to be aware of the bullying acts and to adopt an attitude of compassion and protection towards those who feel marginalized. The encouraging fact is that the percentage of answers indicates a tendency to be more emotionally involved with fiction and a readiness to bring solid arguments to support views.

Reading fiction is a transaction in which the message of the fixed text becomes as flexible as the readers are capable of bending and interpreting it, according to their frame of mind and experiential, cognitive, linguistic and emotional skills. Comparing the students' answers to their results in the TEQ some revealing conclusions may be drawn: the female students who scored above average in the TEQ demonstrated very good command of emotion-related terms and opted for more variants of meaning in the three clusters of emotions; they mostly empathised or even identified with the main character and offered insightful arguments. Similarly, the male students who scored above the upper limit empathised with the main character.

The female students who had an average score in the empathy questionnaire demonstrated high command or fairly good command of the emotion vocabulary, either empathising or identifying with the main character; 
few of them offered less consistent arguments for their feelings. The male reader who scored in the average area demonstrated high command of the emotion vocabulary and tended to empathise offering consistent arguments for his choice.

Probably the most diverse segment of respondents is the one that scored below the average. The female readers scoring under the average limit situated themselves in-between a rather restricted command of emotional vocabulary to a fairly good or even high one. The same multifariousness dominated the areas of empathising or identifying with the main character. Here answers ranged from feeling sorry or unhappy, to empathising (slightly more than a half) or identifying (three students) to no identification or no answer. The male readers with scores below average reflect fairly similar tendencies as the female: their command of emotion vocabulary ranges from fairly good to extensive, most of them identifying (one reader) or empathising (four readers) with the main character, or none (one reader).

Projected on the results from the Reading literary texts - Self-report questionnaire, the outcomes of the study testify to the tendency of being situated between the rather neutral area of 'sometimes' and the more confident one of 'always' with regard to the level of perception, appraisal and expression of emotions and indicate a great need for developing students' emotional intelligence competences for expanding their lexical knowledge with regard to various shades of meaning beyond emotions.

As could be observed, those who volunteered to watch the film in advance and wrote the review have been supported in their answers by the experience offered by it. Moreover, the vocabulary they used in dealing with the task was far more extensive and the reasons they offered were compelling and insightful. Nevertheless, almost half of those who did not watch the movie also opted for more lexical variants in the clusters, which proves that their linguistic competence in English can assist them in any kind of reading comprehension task. In addition, it is a proof of the force exercised by a short text on the perception and interpretation abilities of readers.

\section{CONCLUSIONS}

The acquisition of emotional intelligence literacy skills seems to be of paramount importance, especially for young people, as it will ensure the understanding of other people's emotions and actions, and facilitate the dialogue between oneself and the world. The emotionally intelligent person will be able to identify and express emotions, understand emotions, assimilate them in thought and regulate a wide spectrum of emotions in oneself and other people, in all kind of interactions ranging from reading to communicating. Emotional intelligence has to do with the level of awareness of the self and others in fiction and in real 
life and with the people's abilities to process information to perform tasks and act for one's own good and that of the others.

\section{Works Cited}

Bleich, David. "The Subjective Character of Critical Interpretation”. Twentieth Century Literary Theory. A Reader, edited by Newton, K. M. 2nd ed., New York: Macmillan Education, 1997, pp. 200-203.

Booth, Wayne C. The Rhetoric of Fiction. 2nd ed., London: The University of Chicago Press, 1983.

Cupchik, C. Gerald, Garry Leonard, Elise Axelrad and Judith D. Kalin. “The Landscape of Emotion in Literary Encounters”. COGNITION AND EMOTION, vol.12, no. 6, 1998, pp. 825-847.

Fish, Stanley. "Interpreting the Variourum”. Twentieth-Century Literary Theory. A Reader, edited by Newton, K. M. 2nd ed., New York: Macmillan Education, 1997, pp. 203-209.

---. Is There a Text in This Class? The Authority of Interpretive Communities. Cambridge Massachusetts and London, England: Harvard University Press, 1980.

Goleman, Daniel. Emotional Intelligence. Why it can matter more than IQ. New York: Bantam Books, 1995.

Hogan, Patrick Colm. What Literature Teaches Us about Emotion. New York: Cambridge University Press, 2011.

---. Affective Narratology. The Emotional Structure of Stories. Lincoln and London: University of Nebraska Press, 2011.

---. Cognitive Science, Literature, and the Arts. A Guide for Humanists. New York and London: Routledge, 2003.

---. The Mind and Its Stories. Narrative Universals and Human Emotion. New York: Cambridge University Press, 2003.

---. The Culture of Conformism. Understanding Social Consent. Durham and London: Duke University Press, 2001.

Holland, Norman N. Literature and the Brain. Florida: The PsyArt Foundation, 2009.

---. "The Power(?) of Literature: A Neuropsychological View". New Literary History, Critical Inquiries, Explorations, and Explanations, vol. 35, no. 3, 2004, pp. 395-410.

---. The Critical I. New York: Columbia University Press, 1992.

---. “A Transactive Account of Transactive Criticism”. Poetics, vol. 7, no. 2, NorthHolland Publishing Company, 1978, pp. 177-189.

---. “Transactive Teaching: Cordelia's Death”. College English, Teaching Literature, vol. 39, no. 3, November 1977, pp. 276-285.

"How Empathetic are You? (The Toronto Empathy Questionnaire, TEQ)". www.emotivity.my/wp-content/uploads/How-Empathetic-are-You-TheToronto-Empathy-Questionnaire-TEQ.pdf. Accessed 26 Nov. 2019. 
“'I Feel’ - Emotional Word Wheel”. 1 March 2015, www.imgur.com/gallery/q6hcgsH. Accessed 9 July 2018.

Iser, Wolfgang. “Indeterminacy and the Reader's Response”. Twentieth-Century Literary Theory. A Reader, edited by Newton, K. M, 2nd ed., New York: Macmillan Education, 1997, pp. 195-199.

Jauss, Hans Robert. Aesthetic Experience and Literary Hermeneutics. Minneapolis: University of Minnesota Press, 1982.

Karolides, Nikolas J. and Louise M. Rosenblatt. “Theory and Practice: An Interview with Louise M. Rosenblatt”. Language Arts, vol. 77, no. 2, Collaborations (November 1999), pp. 158-170.

Keen, Suzanne. Empathy and the Novel. New York: Oxford University Press, 2007.

Mar, Raymond A., Keith Oatley, Maja Djikic and Dustin Mullin. "Emotion and narrative fiction: Interactive influences before, during and after reading.” COGNITION AND EMOTION, vol. 25, no. 5, 2011, pp. 818-83.

Mayer, John D. and Peter Salovey. "What is Emotional Intelligence?". Emotional Development and Emotional Intelligence. Educational Implications, edited by Peter Salovey and David Sluyter, New York: Basic Books: A Division of HarperCollinsPublishers, 1997, pp. 3-31.

Nussbaum, Martha C. UPHEAVALS OF THOUGHT. The Intelligence of Emotions. Cambridge: Cambridge University Press, 2001.

---. Cultivating Humanity. A CLASSICAL DEFENSE OF REFORM IN LIBERAL EDUCATION. Cambridge, Massachusetts: Harvard University Press, 1997.

Oatley, Keith. The Passionate Muse. Exploring Emotions in Stories. New York: Oxford University Press, 2012.

---. Such Stuff as Dreams. The Psychology of Fiction. West Sessex: Wiley-Blackwell, John Wiley \& Sons, 2011.

---. Emotions. A Brief History. Oxford: Blackwell Publishing, 2004.

---. "A taxonomy of the emotions of literary response and a theory of identification in fictional narrative.” Poetics, vol. 23, 1994, pp. 53-74.

Palacio, R. J. Wonder. London: Random House Children's Publishers, 2014.

Pelin, R. S.. Literature and Emotional Literacy - The Transforming Power of Literature Over Young Readers’ Minds and Behaviour, PhD Thesis, Iaşi, 2020.

Rosenblatt, Louise M. “The Aesthetic Transaction”. The Journal of Aesthetic Education, vol. 20, no. 4, 20th Anniversary Issue, Winter, 1986, pp. 122-128.

---. “The Literary Transaction: Evocation and Response”. Theory into Practice, vol. 21, no. 4, Children's Literature, Autumn, 1982, pp. 268-277.

---. “Literature: The Reader’s Role”. The English Journal, vol. 49, no. 5, May, 1960, pp. 304 310+315-316.

Salovey, Peter, and Mayer, John D. "Emotional intelligence”. Imagination, Cognition, and Personality, vol. 9, 1990, pp.185-211.

Sklar, Howard. The Art of Sympathy in Fiction. Forms of ethical and emotional persuasion. Amsterdam: John Benjamins B.V., 2013.

Turliuc, M N., Marici, M. "What do Romanian Parents and Adolescents Have Conflicts About?”. Revista de cercetare şi intervenție socială, vol. 42, 2013, pp. 28-49. 


\section{BIONOTE}

Raluca-Ștefania PELIN holds a PhD from the Alexandru Ioan Cuza University of Iaşi, the Faculty of Letters - English Department. The title of her thesis is Literature and Emotional Literacy - The Transforming Power of Literature Over Young Readers' Minds and Behaviour. The focus of her ongoing research is the integration of concepts related to emotional intelligence and emotional literacy skills into the study of English and the response of young readers to literary and non-literary texts from the proposed perspective. Her interest in observing the way in which patterns of emotional intelligence are intrinsic to various types of texts has materialized in the publication of several articles: "The Coral Island” vs. "Lord of the Flies" - Variations in Emotional Intelligence Skills Manifested by Characters Trapped in a Similar Context; Emotionally (Un)Intelligent Characters and the Power of Context to Shape Identities in Kazuo Ishiguro's "The Remains of the Day"; Emotions and Emotional Intelligence Beyond Words in the Poetry of Rose Ausländer, Selma-Meerbaum Eisinger, Paul Celan, and Dan Pagis. She is currently teaching English for specific purposes at "Ion Ionescu de la Brad" Iaşi University of Life Sciences (IULS).

Email: ralustefpel@gmail.com 